\title{
ANALISIS PELUMASAN ELASTOHYDRODYNAMIC PADA SAMBUNGAN TULANG PANGGUL BUATAN UNTUK POSISI SUJUD DALAM SALAT DENGAN MENGGUNAKAN TEKNIK CFD DAN FSI
}

\author{
Mohammad Tauviqirrahman \\ Departemen Teknik Mesin, Fakultas Teknik \\ Universitas Diponegoro \\ Email: mohammad.tauviqirrahman@ft.undip.ac.id \\ Rifki Ardiansyah Budiman \\ Departemen Teknik Mesin, Fakultas Teknik \\ Universitas Diponegoro \\ Email: rifky.ardh@gmail.com
}

\begin{abstract}
ABSTRAK
Pelumasan pada sambungan tulang panggul buatan (artificial hip joint) diperlukan untuk menjaga reliabilitas dan umur pakai komponen prostesis ini ketika digunakan oleh pengguna. Berdasarkan tinjauan pustaka, kebanyakan studi tentang sambungan tulang panggul buatan mengasumsikan kondisi tanpa pelumas (synovial fluid), sehingga bisa mengakibatkan kesimpulan penelitian yang keliru. Penelitian ini bertujuan untuk menganalisis pengaruh keberadaan pelumas pada sambungan tulang panggul buatan terhadap karakteristik pelumasan, serta struktur dari komponen penyusun sambungan. Untuk memperoleh hasil yang akurat, teknik CFD (Computational Fluid Dynamic) dan FSI (Fluid Structure Interaction) digunakan untuk menganalisis mekanisme pelumasan elastohydrodynamic pada sambungan. Fokus penelitian ini adalah analisis karakteristik sambungan tulang panggul buatan yang bergerak saat pengguna melakukan gerakan sujud dalam salat. Seperti diketahui, pengguna sambungan tulang panggul buatan disarankan oleh para dokter untuk membatasi gerakan ekstrim yang dapat merusak sambungan buatan ini. Gerakan tersebut misalnya jongkok, berlari, dan beberapa gerakan salat. Hasil simulasi menunjukkan bahwa untuk meningkatkan keakuratan hasil analisis sambungan tulang panggul buatan dalam tubuh, maka pelumas synovial fluid sangat penting untuk dipertimbangkan dan dimodelkan. Selain itu, keberadaan pelumas ini saat gerakan sujud terbukti membantu mencegah kontak antar permukaan sehingga kemungkinan terjadinya tubrukan (impingement) antar komponen dapat dicegah.
\end{abstract}

Kata kunci: pelumasan, synovial fluid, sambungan tulang panggul buatan; simulasi numerik, sujud.

\section{ABSTRACT}

The lubrication in the artificial hip joint is very crucial in achieving the reliability and longer life time of the prosthesis when the joint is implemented to the user. Based on literature survey, most of studies dealing with the artificial hip joint assumed the condition without lubricant (i.e. synofial fluid), as a consequence it may lead to wrong conclusion. This research is aimed to investigate the effect of the excistence of the lubricant in the artificial hip joint on the lubrication performance as well as the structure of artificial hip joint. In order to obtain the accurate result, CFD and FSI techniques are used to solve the mechanism of elastohydrodynamic lubrication in artificial joint. The characteristic of the artificial hip joint during prostration in salat is of particular interest. As is known, the users of artificial hip joint are recommended by doctors to limit the extreme movements that can damage the artificial hip joint, such squat, running and several movements of salat. The simulation results show that in order to obtain more accurate result, the lubricant of synovial fluid should be considered and modelled. In addition, the existence of the lubricant in the artificial hip joint is proven to prevent the solid contact as well as impingment between the components during prostration activity in salat.

Keywords: lubrication, synovial fluid; artificial hip joint; numerical simulation; prostration.

\section{PENDAHULUAN}

Dewasa ini, gaya hidup masyarakat masa kini yang cenderung tidak sehat dan kurangnya kewaspadaan menjadi sebab utama terjadinya bebagai macam gangguan pada sambungan tulang buatan. Pada kondisi yang sudah serius, nyeri dan berbagai macam penyakit pada sambungan tulang panggul dapat mengakibatkan penderitanya mengalami kesulitan menggerakkan kaki, bahkan kesulitan untuk dapat berjalan. Kerusakan permanen pada sambungan tulang panggul akibat proses pengapuran, penuaan 
atau kecelakaan memerlukan tindakan penggantian dengan sambungan tulang panggul buatan (artificial hip joint).

Sambungan tulang panggul buatan merupakan sambungan yang cukup penting dalam sistem anatomi manusia. Sambungan ini terletak diantara panggul dan pangkal tulang paha yang menghubungkan tulang paha dan tulang pelvis, dan menjadikannya tumpuan beban paling besar (weight bearing). Sambungan tulang panggul buatan terdiri dari empat bagian utama, yaitu femoral stem, femoral head, acetabular shell dan acetabular liner, seperti disajikan dalam Gambar 1.

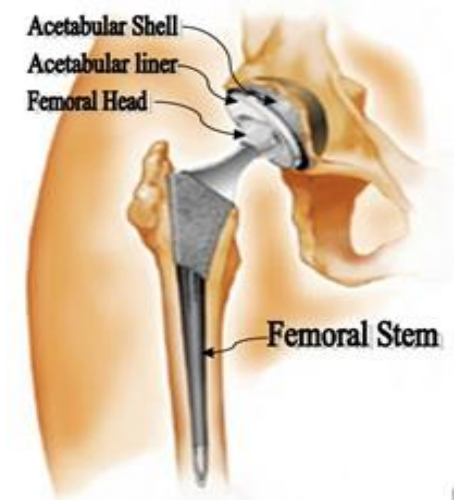

\section{Gambar 1. Sambungan Tulang Panggul Buatan [1]}

Bagi pasien yang menggunakan sambungan tulang panggul buatan, para dokter menyarankan untuk membatasi gerakan pada pasien agar tidak terjadi kerusakan pada sambungan. Gerakan tersebut misalnya jongkok, berlari dan beberapa gerakan dalam salat seperti rukuk dan sujud. Hal ini disebabkan gerakan tersebut menyebabkan sambungan tersebut berpotensi mengalami dislokasi. Untuk mengurangi kemungkinan dislokasi dan kerusakan sambungan tulang panggul buatan, beberapa peneliti yang ada dalam Laboratorium Perancangan Teknik dan Tribologi, Teknik Mesin, Universitas Diponegoro telah mengembangkan desain sambungan tulang panggul buatan dengan dimensi orang Indonesia (selanjutnya disebut model UNDIP) yang diharapkan dapat digunakan untuk melakukan kegiatan salat secara sempurna, mengingat mayoritas masyarakat Indonesia beragama Islam.

Penelitian yang dilakukan Legowo [2] telah mengevaluasi batasan-batasan yang ditemukan sambungan tulang panggul buatan model UNDIP untuk gerakan salat dengan fokus pada reaksi yang diterima oleh acetabular liner dan femoral head. Sedangkan Dhaneswara [3] telah melakukan penelitian tentang pengaruh cleareance terhadap keausan dan impingement (tubrukan) saat melakukan gerakan salat pada sambungan tulang panggul buatan model UNDIP jenis bipolar menggunakan metode elemen hingga. Gapa [4] juga melakukan penelitian yang mengobservasi gerakan berjalan dan salat pada hip joint dengan menggunakan analisis statik, serta mencari gaya reaksi yang terjadi saat melakukan gerakan salat. Analisis yang lebih detil telah dilakukan oleh Eko dkk. [5]. Mereka membandingkan performa sambungan tulang panggul buatan untuk dua jenis kegiatan: Western style dan Japanese style. Hasil simulasi mereka menunjukkan bahwa dislokasi berupa tubrukan antar komponen (impingiment) hanya ditemukan pada aktifitas Western style, sedangkan Japanese style tidak.

Penelitian-penelitian tersebut di atas, meskipun demikian, hanya menfokuskan pada analisis struktur solid (disebut dry contact), tanpa adanya cairan pelumas yang terdapat pada celah komponen-komponen penyusun sambungan tulang panggul tersebut. Padahal dalam kenyataannya, cairan pelumas berupa synofial fluid yang terbentuk secara alami dalam tubuh akan memiliki pengaruh yang cukup signifikan dalam performa sambungan tulang panggul buatan [6-11]. Dengan kata lain, asumsi dry contact dalam analisis sambungan tulang panggul buatan menjadi kurang valid dan bisa menjurus kepada penarikan kesimpulan hasil penelitian yang salah.

Berdasarkan tinjauan pustaka sebelumnya, maka fokus penelitian ini adalah untuk menganalisis pengaruh keberadaan pelumas synovial fluid terhadap karakteristik pelumasan (tekanan hidrodinamik), serta kekuatan struktur (deformasi, tegangan von Mises) sambungan tulang panggul buatan. Karakteristik sambungan tulang panggul buatan selama gerakan sujud sebagai bagian dari kegiatan salat adalah objek penelitian ini. Selain itu, untuk dapat menangkap perilaku fisik sambungan secara lebih detil, maka model pelumasan jenis elastohydrodynamic dipilih dalam studi ini. Dengan penelitian ini diharapkan selain dapat membantu pengguna dalam aktivitas sehari-hari, juga memastikan bahwa sambungan buatan buatan tidak akan mengalami deformasi yang berlebihan yang dapat mengakibatkan tubrukan saat digunakan untuk melakukan sujud dalam gerakan salat. 


\section{METODOLOGI PENELITIAN}

Penelitian ini menggunakan dua teknik pemecahan masalah, yaitu computational fluid dynamic (CFD) dan fluid structure interaction (FSI). CFD digunakan untuk analisis mekanika fluida dalam pelumas (synovial fluid), sedangkan FSI digunakan untuk analisis struktur komponen-komponen penyusun sambungan tulang panggul buatan dengan masukan kondisi batas yang berasal dari hasil CFD. Dengan interaksi antara mekanika fluida dan solid dalam satu analisis, hasil-hasil yang lebih akurat dapat diperoleh. Keluaran analisis CFD adalah berupa tekanan hidrodinamik, sedangkan keluaran analisis FSI adalah deformasi dan tegangan. Dengan kombinasi teknik CFD dan FSI ini, maka analisis pelumasan elastohydrodynamic dapat dilakukan yang pada penelitian-penelitian sebelumnya, analisis hanya berada pada daerah hydrodynamic. Analisis elastohydrodynamic memungkinkan perubahan ketebalan film pelumas akibat deformasi yang mungkin terjadi pada komponen-komponen sambungan tulang panggul dapat dihitung sehingga hasil perhitungan menjadi lebih akurat karena sesuai dengan realitas fisik yang terjadi pada sambungan tulang panggul buatan.

\subsection{Model Pelumasan Elastohydrodynamic}

Model pelumasan elastohydrodynamic yang dianalisis dalam penelitian ini pada dasarnya merupakan persamaan umum klasik dalam dinamika fluida yaitu persamaan Navier-Stokes (Persamaan (1)) dan kontinuitas (Persamaan (2)). Kedua persamaan ini dipecahkan dengan menggunakan metode volume hingga. Persamaan tersebut mengasumsikan densitas dan viskositas konstan, dengan melibatkan gaya bodi. Kondisi steady dan pemecahan dalam arah dua dimensi $(x$ dan $z$ ) juga digunakan. Persamaan Navier-Stokes dan kontinuitas diekspresikan sebagai berikut:

$$
\begin{aligned}
& \rho \frac{D u_{i}}{D t}=-\frac{\partial p}{\partial x_{i}}+\rho G_{i}+\frac{\partial}{\partial x_{j}}\left[2 \eta e_{i j}-\frac{2}{3} \eta\left(\nabla \cdot u_{i}\right) \delta i j\right] \\
& \frac{\partial \rho}{\partial t}+\frac{\partial}{\partial x_{i}}\left(\rho u_{i}\right)=0
\end{aligned}
$$

Sedangkan untuk analisis struktur yang dapat digunakan untuk menghitung besarnya deformasi pada komponen-komponen sambungan tulang panggul buatan termasuk besarnya tegangan, digunakanlah persamaan umum sebagai berikut:

Ku $u=F$

dimana $K$ adalah matriks kekakuan, $u$ adalah perpindahan dan $F$ adalah gaya. Dalam studi ini, Persamaan (3) akan dipecahkan dengan menggunakan metode elemen hingga.

\subsection{Pemodelan Geometri Sambungan Tulang Panggul Buatan}

Dalam penelitian ini, sambungan tulang panggul buatan terdiri dari poros head yang berputar secara spherical terhadap housing cup. Kedua permukaannya terpisah oleh pelumas. Tekanan hidrodinamik terbentuk karena adanya dinamika pelumas yang selanjutnya berguna untuk menahan beban eksternal pada poros yang berputar. Karena terdapat gaya yang terjadi akibat gerakan sholat, besar tekanan ini juga akan meningkat. Tekanan maksimum juga terpengaruh dengan viskositas pelumas. Gambar 2 menunjukkan skema sambungan tulang panggul buatan. 


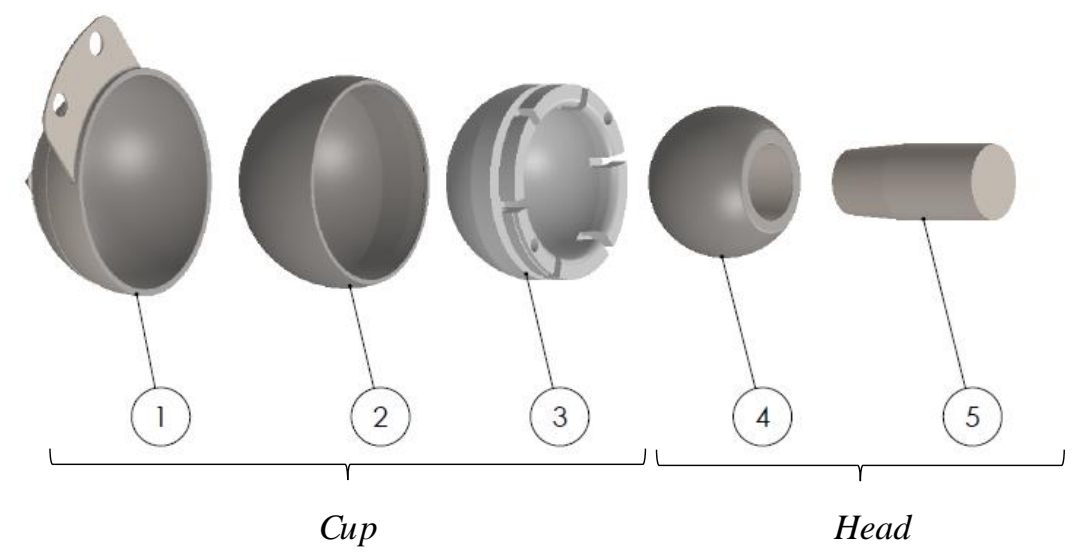

Gambar 2. Komponen-Komponen Sambungan Tulang Panggul Buatan

(Catatan: 1. Acetabular Cup, 2. Outer Liner, 3. Inner Liner, 4. Femoral Head, 5. Batang Stem)

Untuk mendefinisikan posisi sambungan tulang panggul buatan saat gerakan sujud, diperlukan masukan sudut berupa flexion, abduction, dan rotation. Sudut ini diperoleh dengan cara memutar posisi femoral head yang diukur berdasarkan posisi normal sambungan tulang panggul buatan atau disebut juga posisi anatomi (posisi berdiri). Dengan demikian, untuk gerakan sujud, sudutnya adalah sebagai berikut:
a. Flexion $(\operatorname{sumbu} x)$
$=118.6^{\circ}$
b. Abduction (sumbu y)
$=-3.3^{\circ}$
c. Rotation (sumbu $z$ )
$=0^{\circ}$

Pemodelan geometri sambungan tulang panggul buatan untuk kasus gerakan sujud dapat dilihat dalam Gambar 3 di bawah ini.

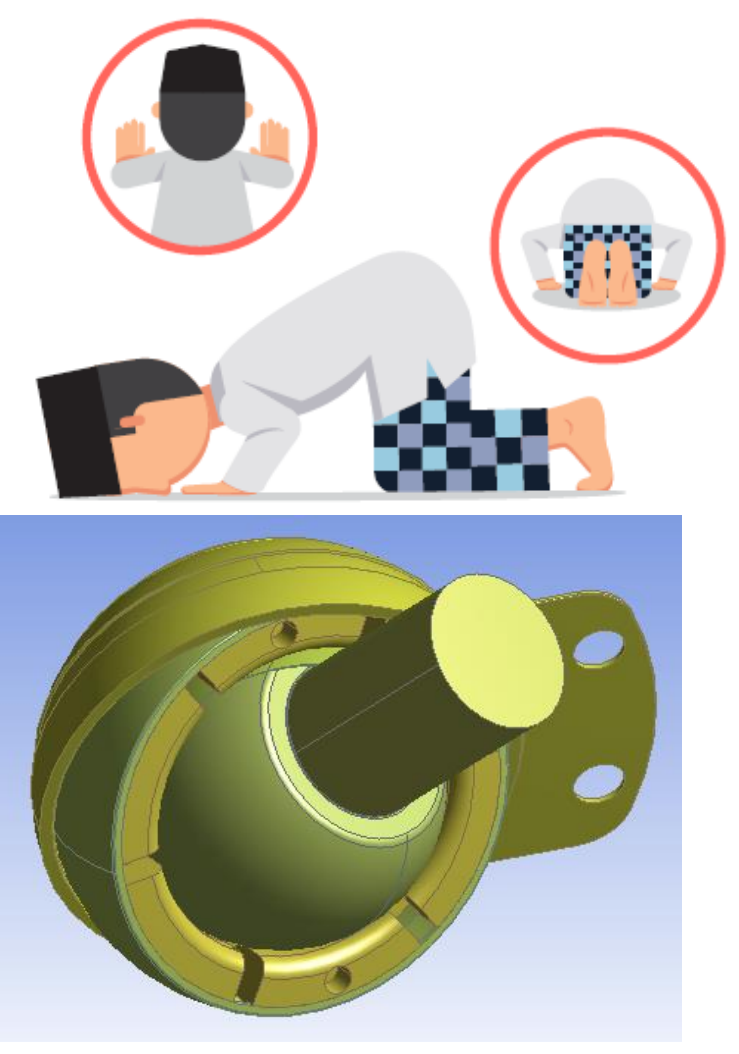

Gambar 3. Pemodelan Sambungan Tulang Panggul Buatan Dalam Posisi Sujud 


\subsection{Kondisi Batas Pada Domain Fluid}

Simulasi sambungan tulang panggul buatan ini mengasumsikan dua permukaan yang memiliki kondisi batas no-slip. Gambar 4 menyajikan secara detail kondisi batas yang digunakan untuk keseluruhan simulasi. Pelumas synofial fluid dimodelkan sebagai fluida non-Newtonian. Pomodelan Cross dipilih untuk memodelkan sifat non-Newtonian ini, dan pelumas ini memiliki karakteristis fluida sebagai berikut:
a. Zero Shear Viscocity
b. Power-law index (n)
$=40 \mathrm{~kg} / \mathrm{m}-\mathrm{s}$
c. Tme Constant
$=0.27$
d. Massa jenis
$=9.54 \mathrm{~s}$
$=1,010 \mathrm{~kg} / \mathrm{m}^{3}$

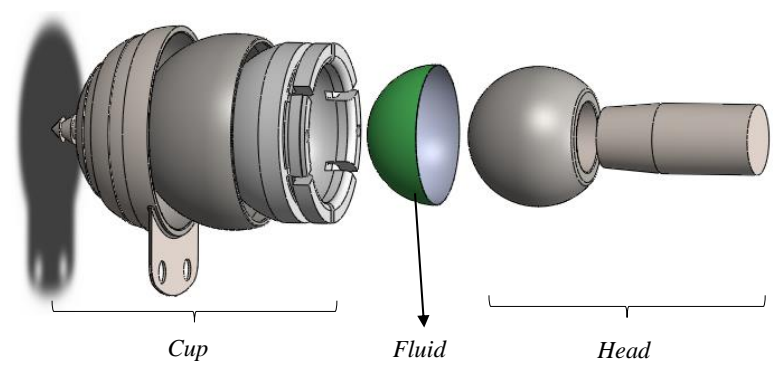

(a)

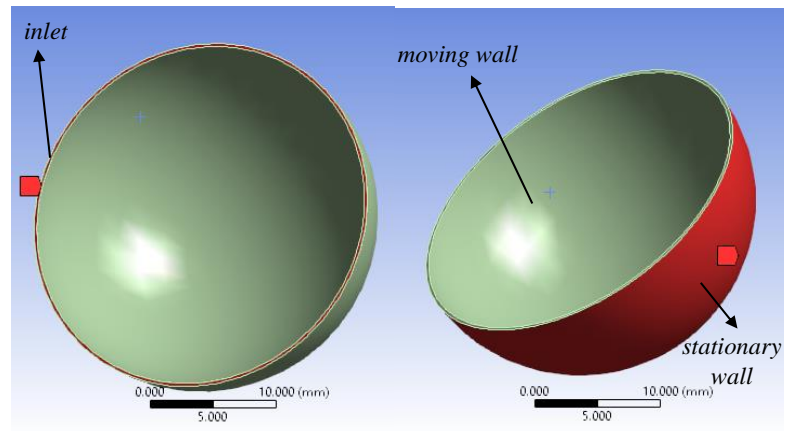

(b)

(c)

Gambar 4. Kondisi Batas Pada Pelumas Untuk Analisis CFD: A) Letak Pelumas Pada Sambungan Tulang Panggul, B) Inlet, C) Moving Wall Dan Stationary Wall

Dalam penelitian ini, untuk mendefinisikan kondisi batas gerakan sujud, maka diperlukan vektor kecepatan untuk mendeskripsikan gerakan sambungan tulang panggul buatan. Tabel 1 menyajikan kondisi batas kecepatan yang diperlukan oleh sambungan tulang panggul buatan untuk bergerak saat sujud.

Tabel 1. Komponen vektor kecepatan untuk analisis dinamika gerakan sujud

\begin{tabular}{cccc}
\hline \multirow{2}{*}{ Gerakan } & \multicolumn{3}{c}{ Komponen kecepatan } \\
\cline { 2 - 4 } Sujud & Flexion $(\boldsymbol{X})(\mathrm{m} / \mathrm{s})$ & Abduction $(\boldsymbol{Y})(\mathrm{m} / \mathrm{s})$ & Rotation $(\mathrm{Z})(\mathrm{m} / \mathrm{s})$ \\
\hline
\end{tabular}

Dalam Teknik FSI, diperlukan pendefinisian daerah kontak antara fluida dan solid dengan menggunakan dynamic mesh. Dalam penelitian ini, daerah kontak antara fluida dan solid adalah daerah pada permukaan bagian dalam cup dan permukaan bagian luar fluid, serta bagian luar head dengan bagian dalam fluid (lihat Gambar 4).

\subsection{Kondisi Batas pada Domain Solid}

Kondisi batas untuk analisis struktur adalah jenis tumpuan pada model. Dalam penelitian ini, jenis tumpuan yang digunakan adalah tumpuan jepit (fixed support) yang diberikan pada bagian terluar 
acetabular cup agar tidak terjadi pergerakan atau perpindahan. Selanjutnya untuk mengaktifkan sistem coupling dalam fluid solid interface (FSI), daerah pada solid yang mempunyai kontak langsung dengan fluida perlu didefinisikan. Daerah tersebut adalah permukaan bagian dalam cup dan permukaan bagian luar fluida, serta bagian luar head dengan bagian dalam fluida. Gambar 5 di bawah ini menunjukkan pendefinisian kondisi batas yang detil untuk analisis fluid solid interface.

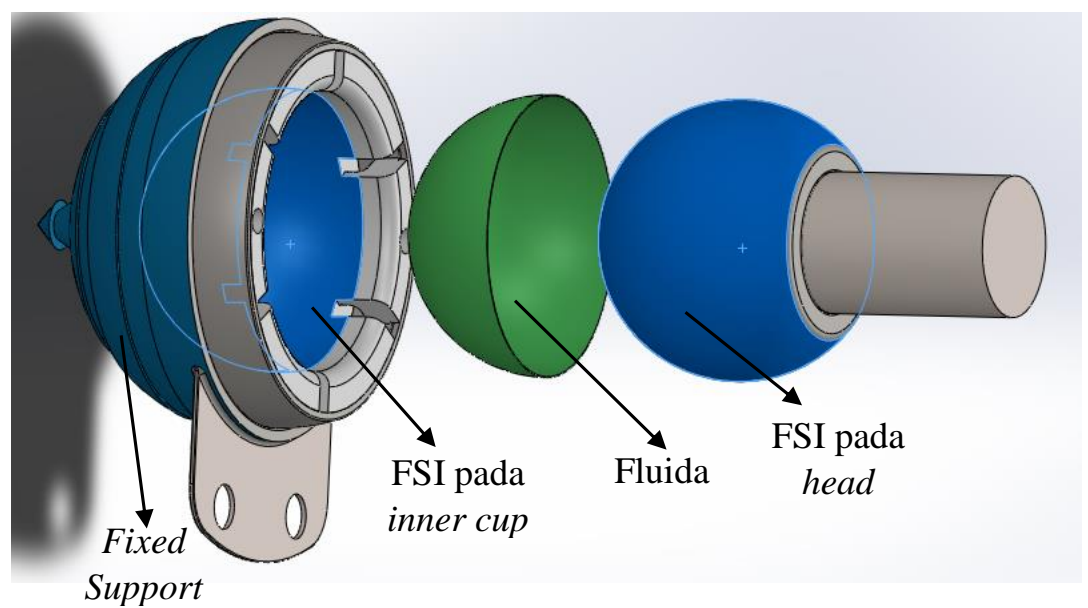

Gambar 5. Kondisi Batas Untuk Analisis CFD Dan FSI

Dalam teknik FSI, perlu dilakukan setup pada system coupling agar sinkronisasi data yang akan ditransfer pada fluid-solid interface pada head dan fluid-solid interface pada cup dapat terlaksana. Pada system coupling ini, data transfer dari fluid ke solid berupa tekanan atau gaya dan efek dari gaya tersebut akan dikembalikan dari solid ke fluid berupa perpindahan. Penentuan transfer data ini ditentukan pada setiap daerah kontak antara solid dan fluid. Setelah ketiga solver yaitu fluid solver, structure solver dan system coupling ditentukan maka iterasi bisa dimulai sampai mencapai kriteria konvergensi.

\section{HASIL DAN PEMBAHASAN}

\subsection{Hasil Distribusi Dan Kontur Tekanan Synovial Fluid}

Gambar 6 menunjukkan distribusi tekanan hidrodinamik yang dihasilkan oleh pelumas untuk gerakan sujud di sepanjang sambungan. Dari gambar ini, tampak bahwa garis tekanan hidrodinamik berada di atas nol. Dari segi fisik, ini berarti bahwa pelumas mampu untuk mengimbangi beban eksternal yang ditumpu oleh sambungan tulang panggul selama gerakan sujud. Dapat dilihat pula bahwa tekanan

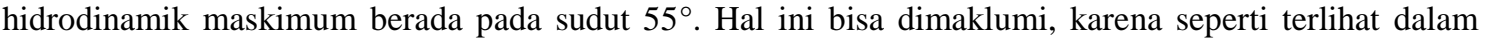
Gambar 3 posisi sudut stem membentuk sudut pada kisaran nilai tersebut. Untuk lebih detilnya, letak kisaran berbagai harga tekanan hidrodinamik disajikan dalam Gambar 7. Kontur berwarna merah menandakan tingginya tekanan dan kontur berwarna biru menandakan rendahnya tekanan. Hal ini disebabkan karena adanya kenaikan tekanan pada titik yang terkena arah gaya reaksi akibat gerakan sujud. Yang perlu digaris bawahi disini adalah bahwa dengan besarnya nilai tekanan maksimum, maka komponen-komponen sambungan tulang panggul buatan tidak akan mengalami kontak solid dengan solid, yang berpotensi menyebabkan rasa sakit pada sambungan oleh pengguna. Dengan demikian, sambungan tulang panggul buatan model UNDIP dapat digunakan oleh pasien waktu gerakan sujud dalam salat. 


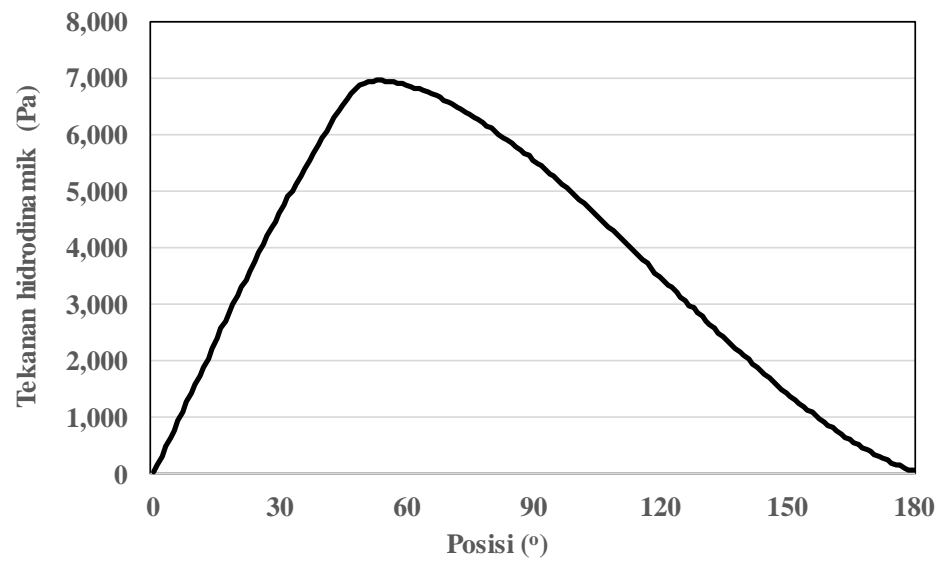

Gambar 6. Distribusi Tekanan Hidrodin Amik Pada Synovial Fluid Saat Sujud Dalam Gerakan Salat

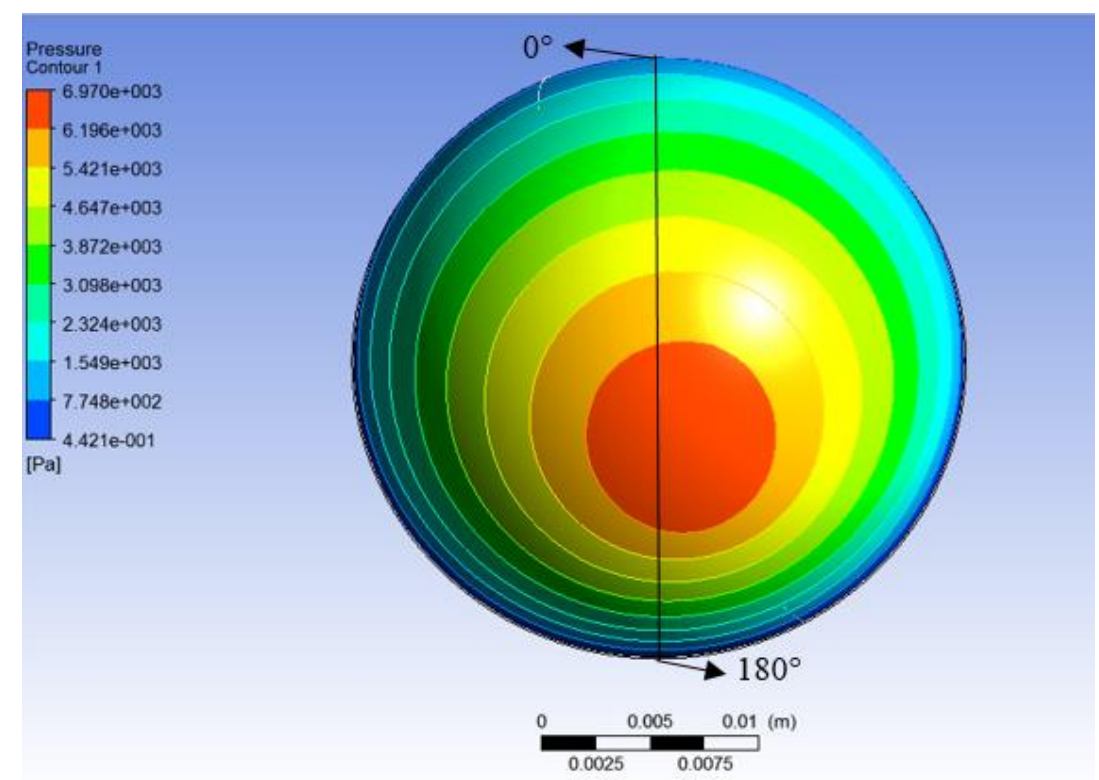

\section{Gambar 7. Kontur Distribusi Tekanan Hidrodinamik Pada Synovial Fluid}

\subsection{Hasil Deformasi Domain Solid}

Gambar 8 menunjukkan kontur deformasi pada sambungan tulang panggul buatan untuk posisi sujud. Dapat dilihat bahwa tekanan hodrodinamik yang diberikan synovial fluid ke inner liner cup dan femoral head cukup besar sehingga mampu memberikan deformasi elastis pada komponen. Deformasi ini terjadi disebabkan oleh gaya beban dan sudut range of motion pada saat gerakan sujud yang cukup besar. Meskipun demikian, jika dibandingkan dengan clearance yang ada (sebesar $0.1 \mathrm{~mm}$ ), deformasi yang terjadi (sebesar $1.61 \times 10^{-3} \mathrm{~mm}$ ) jauh lebih kecil sehingga kemungkinan kecil terjadi metal-to-metal contact antara inner liner cup dan femoral head. Gambar 8 juga memperlihatkan bahwa deformasi maksimum terjadi pada batang stem. Dengan kata lain, tumbukan (impingement) pada sambungan tulang panggul buatan untuk gerakan sujud diprediksikan tidak akan terjadi. 

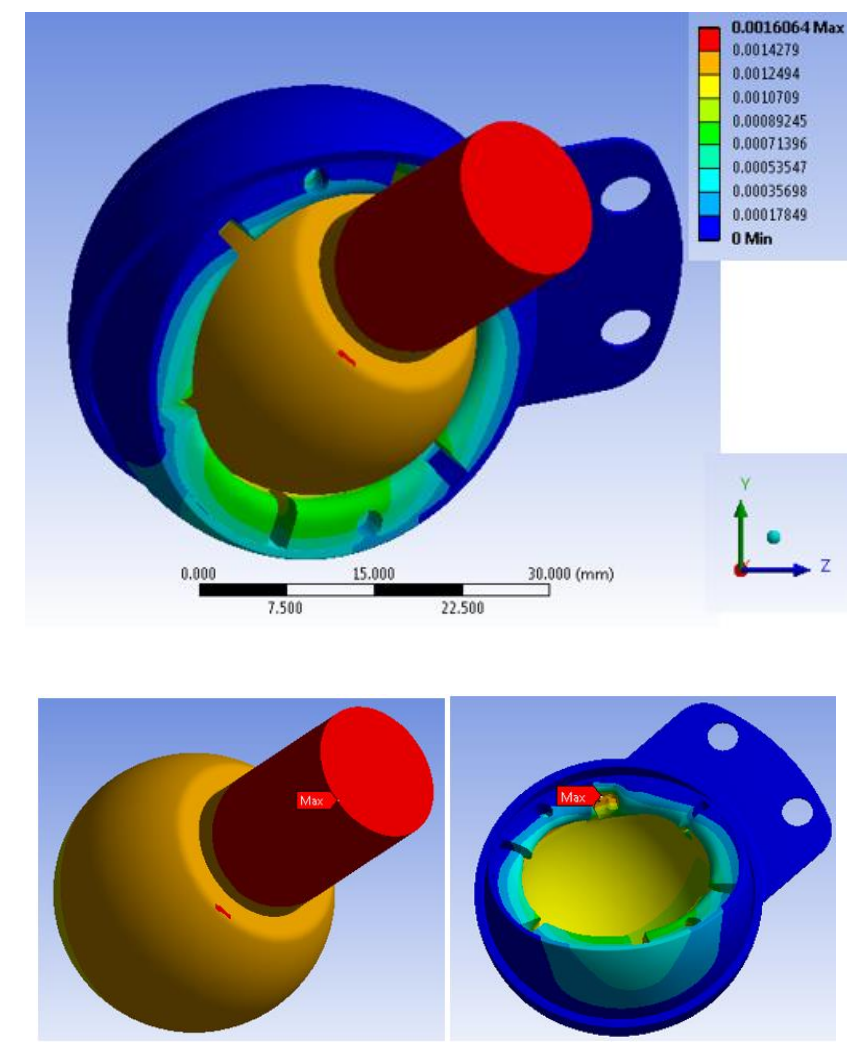

\section{Gambar 8. Kontur Deformasi pada Sambungan Tulang Panggul Buatan}

\subsection{Hasil Tegangan von Mises pada Domain Solid}

Gambar 9 menunjukkan kontur tegangan von Mises dimana kontur berwarna merah menandakan tingginya tegangan dan kontur berwarna biru menandakan rendahnya tegangan. Terlihat bahwa tegangan von Mises maksimum terjadi di acetabular cup dengan nilai sebesar 6.90 MPa. Mengacu pada hasil penelitian yang dilakukan oleh Gapa [4] dimana analisis dilakukan tanpa memperhitungkan pengaruh keberadaan synovial fluid, maka terdapat perbedaan nilai tegangan von Mises yang cukup besar hingga mencapai $1,500 \%$ apabila dibandingkan dengan hasil penelitian saat ini yang memperhitungkan keberadaan synovial fluid, seperti yang tersaji dalam Tabel 2. Penjelasan yang paling mungkin adalah bahwa pelumas synofial fluid memiliki viskositas yang mampu meredam beban eksternal yang datang ketika sujud dilakukan. Redaman ini muncul karena sifat unik yang dimiliki oleh pelumas alami ini, yang mana tegangan geser yang terjadi tidak berbanding lurus dengan laju geser, seperti perilaku pelumas Newtonian. 


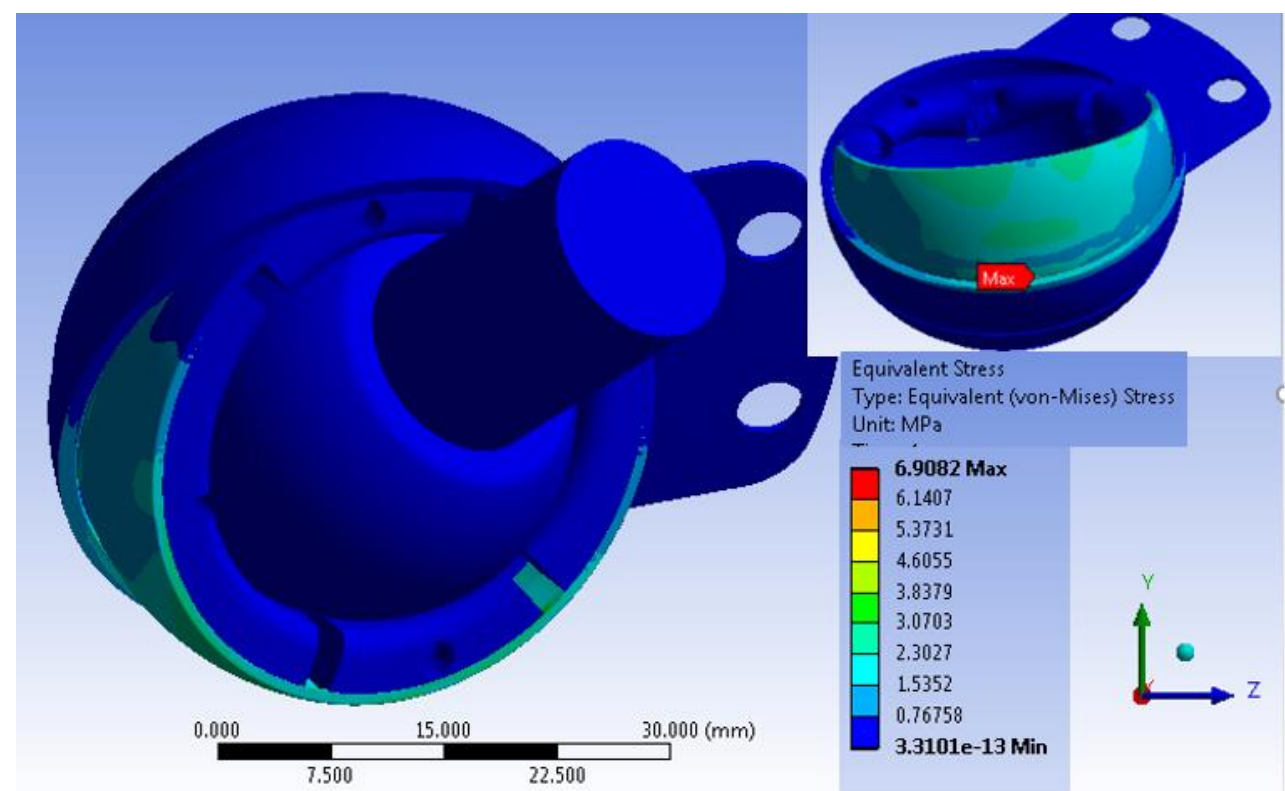

Gambar 9. Kontur Tegangan Von Mises Sambungan Tulang Panggul Buatan (Inset: Letak Tegangan Von Mises Maksimum)

Tabel 2. Perbandingan hasil simulasi tanpa dan dengan synofial fluid

\begin{tabular}{lcc}
\hline \multirow{3}{*}{ Posisi } & \multicolumn{2}{c}{ Tegangan von Mises stress (MPa) } \\
\cline { 2 - 3 } & Tanpa mempertimbangkan & Dengan mempertimbangkan \\
& synofial fluid [4] & synofial fluid (present study) \\
\hline Sujud & 119.8 & 6.9 \\
\hline
\end{tabular}

\section{KESIMPULAN}

Dalam penelitian ini, analisis pelumasan elastohydrodynamic pada sambungan tulang panggul buatan selama gerakan sujud dalam salat telah dilakukan dengan menggunakan metode yang komprehensif, yaitu kombinasi antara metode computational fluid dynamic (CFD) dan fluidstructure interaction (FSI). Kedua metode ini mampu memprediksi dinamika solid dan dinamika fluid pada sambungan sehingga performa pelumasan dapat diprediksi dengan lebih akurat. Dari keseluruhan hasil simulasi dapat disimpulkan beberapa hal sebagai berikut:

a. Keberadaan pelumas synovial fluid sangat penting untuk dimodelkan dalam analisis sambungan tulang panggul buatan. Hal ini terbukti adanya perbedaan yang signifikan terkait prediksi tegangan von Mises dan terjadinya impingement antara analisis yang memperhitungkan synovial fluid dengan yang tidak.

b. Hasil simulasi menunjukkan bahwa sambungan tulang panggul buatan yang dikembangkan cukup aman untuk gerakan sujud dalam salat karena deformasi yang terbentuk cukup kecil jika dibandingkan dengan toleransi (clearance) yang ada.

\section{DAFTAR PUSTAKA}

[1] www.waterburyhospital.org (tanggal akses, 14 April 2009)

[2] Legowo, A.B. (2015). Simulasi dan Evaluasi Acetabular Liner dan Femoral Head Total Hip Arthoplasty Model Undip pada Gerakan Shalat Menggunakan Metode Elemen Hingga. Tugas Akhir S1 Teknik Mesin, Universitas Diponegoro, Semarang.

[3] Dhaneswara, Y.A. (2016). Analisis Pengaruh Clearance Terhadap Keausan dan Impingement Gerakan Salat pada Sendi Panggul Buatan Produk Undip Tipe Bipolar Menggunakan Metode Elemen Hingga. Tugas Akhir S1 Teknik Mesin, Universitas Diponegoro, Semarang.

[4] Gapa, A.E.R. (2017). Biomekanika Sendi Panggul Saat Berjalan Dan Salat. Tugas Akhir S1 Teknik Mesin, Universitas Diponegoro, Semarang. 
[5] Saputra, E., Anwara, I.B., Ismail, R., Jamari, J. dan van der Heide, E. 2014. "Numerical Simulation of Artificical Hip Joint Movement for Western and Japanese-Style Activities". Jurnal Teknologi (Sciences \& Engineering) 66. 3, 53-58.

[6] Gao, L., Yang, P., Dymond, I., Fisher, J. Dan Jin, Z. 2010. "Effect of Surface Texturig on the Elastohydrodynamic Lubrication Analysis of Metal-on-Metal Hip Implants". Tribology International 43, 1851-1860.

[7] Jhurani, S.M., Higgs, C.F. 2010. "An Elastohydrodynamic Lubrication (EHL) Model of Wear Particle Migration in an Artificial Hip Joint". Tribology International 43 (8),1326-1338.

[8] Mattei, L., DiPuccio, F., Piccigallo, B., Ciulli, E. 2011. "Lubrication and Wear Modelling of Artificial Hip Joints: A Review". Tribology International 44, 532-549.

[9] Vrbka, M., Nečas, D., Hartl, M., Křupka, I., Urban, F., Gallo, J. 2015. "Visualization of Lubricating Films Between Artificial Head and Cup with Respect to Real Geometry". Biotribology 1-2, 61-65.

[10] Gao, L., Dowson, D., Hewson, R.W. 2016. "A Numerical Study of Non-Newtonian Transient Elastohydrodynamic Lubrication of Metal-On-Metal Hip Prostheses". Tribology International 93, Part B, 486-494.

[11] Tauviqirrahman, M., Muchammad, Bayuseno, A.P., Ismail, R., Saputra, E. dan Jamari, J. 2016. "Estimation of Appropriate Lubricating Film Thickness in Ceramic-On-Ceramic Hip Prostheses". American Institute of Physic (AIP) Conference Proceedings 1725, 020090-1-020090-4. 